\title{
Matriz de soluções para os problemas da neoseletividade induzida nos cenários de prática na Atenção Primária pelo programa Previne Brasil
}

\author{
Matrix of solutions for the problems of neo selectivity induced in practice scenarios in Primary \\ Care by the Previne Brasil program \\ Matriz de soluciones para los problemas de neo selectividad inducidos en escenarios de práctica en \\ la Atención Primaria por el programa Previne Brasil
}

Recebido: 21/12/2021 | Revisado: 28/12/2021 | Aceito: 05/01/2022 | Publicado: 08/01/2022

\author{
Karina Magrini Carneiro Mendes \\ ORCID: https://orcid.org/0000-0001-6620-0548 \\ Universidade São Francisco, Brasil \\ E-mail: karina.mendes@usf.edu.br \\ Leonardo Carnut \\ ORCID: https://orcid.org/0000-0001-6415-6977 \\ Universidade Federal de São Paulo, Brasil \\ E-mail: leonardo.carnut@unifesp.br \\ Lúcia Dias da Silva Guerra \\ ORCID: https://orcid.org/0000-0003-0093-2687 \\ Centro Universitário Anhanguera, Brasil \\ E-mail: ludsguerra@gmail.com
}

\begin{abstract}
Resumo
A Atenção Primária à Saúde (APS) é considerada o espaço privilegiado de inserção do ensino em saúde, pois é reconhecida como coordenadora da atenção. Ela proporciona uma prática da atenção integral à saúde considerando seus determinantes biopsicossociais, ações de promoção, prevenção, recuperação e de reabilitação, de modo interprofissional, através do trabalho em rede e integrado nos diversos níveis de complexidade do sistema de saúde. Embora, historicamente, se tenha avançado na construção das diversas formas de IESC no SUS, observa-se, na prática, muitas dificuldades relacionadas à sua operacionalização. Na APS, soma-se a esses entraves um conjunto de mudanças que apresenta grande potencial de alteração dos pilares que vinham favorecendo a estabilidade institucional e o alcance de bons resultados sanitários, sobretudo, via Estratégia de Saúde da Família. Com o subfinanciamento histórico do SUS e seu processo de desfinanciamento pela EC-95, o novo modelo de financiamento da APS, de forma neofocalizada e neoseletiva, para a população mais pobre, significa restringir mais ainda os recursos do SUS. Após realizar uma metassíntese qualitativa dos desafios existentes nos cenários de prática da APS descritos nos principais estudos que sistematizam essas experiências no país, coube-nos apresentar possíveis soluções a como irão se reconfigurar os cenários de ensino na APS para a formação dos futuros profissionais de saúde em condições tão adversas ao cuidado, à integralidade, à equidade e com risco real à interprofissionalidade. Neste sentido é que este produto visa reorientar a organização dos serviços da APS afim de minimizar os impactos da neoseletividade no cuidado, serviço e atenção à saúde.
\end{abstract}

Palavras-chave: Educação Superior; Atenção Primária à Saúde; Formação Profissional; Integração docente assistencial; Melhoria de qualidade.

\begin{abstract}
Primary Health Care (PHC) is considered the privileged space for the insertion of health education, as it is recognized as the coordinator of care. It provides a practice of comprehensive health care considering its biopsychosocial determinants, promotion, prevention, recovery and rehabilitation actions, in an interprofessional way, through networking and integrated into the various levels of complexity of the health system. Although, historically, progress has been made in the construction of different forms of IESC in the SUS, in practice there are many difficulties related to its operationalization. In PHC, these obstacles are compounded by a set of changes that have great potential for changing the pillars that have been favoring institutional stability and the achievement of good health outcomes, above all, via the Family Health Strategy. With the historical underfunding of the SUS and its unfunding process by EC-95, the new funding model for the PHC, in a neo-focused and neo-selective way, for the poorest population, means to further restrict SUS resources. After carrying out a qualitative meta-synthesis of the challenges existing in the PHC practice scenarios described in the main studies that systematize these experiences in the country, it was up to us to present possible solutions to how the teaching scenarios in PHC will be reconfigured for the training of future
\end{abstract}


health professionals in conditions that are so adverse to care, comprehensiveness, equity and with a real risk to interprofessionalism. In this sense, this product aims to reorient the organization of PHC services in order to minimize the impacts of neo-selectivity in care, service and health care.

Keywords: Higher Education; Primary Health Care; Professional training; Teaching assistance integration; Quality improvement.

\section{Resumen}

La Atención Primaria de Salud (APS) es considerada el espacio privilegiado para la inserción de la educación para la salud, ya que es reconocida como la coordinadora de la atención. Brinda una práctica de atención integral a la salud considerando sus determinantes biopsicosociales, acciones de promoción, prevención, recuperación y rehabilitación, de manera interprofesional, a través del trabajo en red e integrado en los distintos niveles de complejidad del sistema de salud. Si bien históricamente se ha avanzado en la construcción de diferentes formas de IESC en el SUS, en la práctica existen muchas dificultades relacionadas con su operacionalización. En la APS, estos obstáculos se ven agravados por un conjunto de cambios que tienen un gran potencial para cambiar los pilares que han estado favoreciendo la estabilidad institucional y el logro de buenos resultados en salud, sobre todo, a través de la Estrategia Salud de la Familia. Con la histórica insuficiencia de fondos del SUS y su proceso de desfinanciamiento por parte de la CE-95, el nuevo modelo de financiamiento de la APS, de forma neo-focalizada y neo-selectiva, para la población más pobres, significa restringir aún más los recursos del SUS. Luego de realizar una meta-síntesis cualitativa de los desafíos existentes en los escenarios de práctica de la APS descritos en los principales estudios que sistematizan estas experiencias en el país, nos correspondió presentar posibles soluciones a cómo se reconfigurarán los escenarios de enseñanza en APS para la formación de los futuros profesionales de la salud en condiciones tan adversas para la atención, la integralidad, la equidad y con un riesgo real para la interprofesionalidad. En este sentido, este producto tiene como objetivo reorientar la organización de los servicios de APS con el fin de minimizar los impactos de la neoselectividad en la atención, el servicio y la atención de la salud.

Palabras clave: Educación superior; Atención Primaria de Salud; Formación profesional; Integración asistencial docente; Mejoramiento de la calidad.

\section{Introdução}

A Atenção Primária à Saúde (APS) é considerada o espaço privilegiado de inserção do ensino em saúde, pois é reconhecida como coordenadora e ordenadora da rede de atenção. Ela proporciona uma prática da atenção integral à saúde considerando seus determinantes biopsicossociais, ações de promoção, prevenção, recuperação e de reabilitação, de modo interprofissional, através do trabalho em rede e integrado nos diversos níveis de complexidade do sistema de saúde.

Embora, historicamente, tenha se avançado na construção das diversas formas de Integração Ensino-ServiçoComunidade (IESC) no Sistema Único de Saúde (SUS), observa-se, na prática, muitas dificuldades relacionadas a sua operacionalização. Entre algumas dificuldades estão a inserção docente nos serviços, os valores e objetivos atribuídos às atividades de ensino, a adoção das estratégias de cuidado pelos diferentes sujeitos, além dos desafios inerentes ao processo de mudança do modelo de atenção. Estes elementos atravancam o processo e a evolução das relações na IESC tornando o cenário de práticas no SUS um desafio na formação profissional (Marin, 2013).

Há queixas que dizem respeito, muitas vezes, ao fato de a universidade estar no serviço sem levar em consideração os trabalhadores, ou, ainda, que não há participação do profissional do serviço, a não ser na supervisão do estudante, feita em alguns casos de modo assistemático e solitário, sem uma discussão ou presença mais efetiva do docente. Por outro lado, há críticas à diferença marcante entre a lógica da organização dos serviços, muito centrada na produtividade de seus procedimentos técnico-operativos e a lógica do ensino, ainda centrada na produção de conhecimentos teóricos e metodológicos dos campos pedagógicos e núcleos específicos (Henriques, 2005; Vendruscolo, 2018). Porém, os problemas da IESC não se resumem apenas ao âmbito da integração em nível local.

Durante toda sua história, o SUS sobrevive sob um crônico processo de subfinanciamento que, após a Emenda Constitucional n. 95 (EC-95/2016), passou a ser desfinanciado ao se congelar o gasto público em saúde por 20 anos (Mendes \& Carnut, 2020a). Neste contexto, a APS vem sendo alvo principal de um conjunto de mudanças que, em sinergia com os 
últimos relatórios do Banco Mundial (2017), apresenta grande potencial de alteração dos pilares que vinham favorecendo a estabilidade institucional e o alcance de bons resultados sanitários, sobretudo, via Estratégia de Saúde da Família (ESF).

Mudanças importantes foram instituídas com a nova Política Nacional da Atenção Básica em 2017, que objetiva um processo de reestruturação abrangendo diretrizes, formas de organização, composição das equipes, processos de trabalho e escopo de práticas, com impactos sobre o modelo de atenção e do direito à saúde. Esta edição da política relativiza a universalidade e destitui a ESF como prioridade central na organização da APS, admitindo composição de equipes mínimas diminuídas e carga horária flexível (Morosini, 2020).

Em agosto de 2019, a Lei n 13.958 de 18 de dezembro institui o Programa Médicos pelo Brasil e autoriza o trabalho do serviço social autônomo denominado Agência para o Desenvolvimento da Atenção Primária à Saúde (ADAPS), tendo como modelo a personalidade jurídica do direito privado sem fins lucrativos. Segundo Morosini et al (2020), a ADAPS permite importante transferência de responsabilidades gestoras do Ministério da Saúde para esta agência, tornando a APS espaço para atuação direta de empresas privadas de saúde na assistência, com acesso a fontes públicas, estáveis e volumosas de financiamento.

Seguindo a mesma lógica, apresenta-se a Carteira de Serviços da Atenção Primária à Saúde (CaSAPS), fundamental para a precificação de serviços passíveis de contratação de terceiros com base em capitação associada a pacote de procedimentos. Melo et al (2019) apontam para o risco do avanço da mercantilização, podendo reduzir ainda mais o poder dos gestores locais e ampliar sua dependência aos agentes privados com um processo de precificação facilitado.

À medida que aglutina todas, apresenta na portaria n. 2.979/2019 (Brasil, 2019b) o seu auge. Nesta, o novo modelo de financiamento da Atenção Básica, o "Programa Previne Brasil", implementa as diretrizes do Relatório do Banco Mundial, extinguindo o Piso da Atenção Básica per capita (PAB-fixo) e substituindo o antigo Piso da Atenção Básica Variável por adesão à programas (PAB-variável) (ex. equipes de saúde bucal, equipes de consultório de rua, entre outros) por um pagamento por capitação ponderada calculado pelo número de pessoas cadastradas nas unidades de saúde (vulneráveis) e cujo valor transferido é variável em função do alcance de métricas de desempenho, eliminando a lógica de transferências do valor per capita populacional do município e por adesão às estratégias (Brasil, 2019b).

É pertinente lembrar que a indução de novas seletividades, ou práticas neoseletivas, são consequências em nível local (algumas já previstas em estudos recém-publicados ou como uma "tendência" ainda a ser verificada) da nova política de financiamento deste nível de atenção conforme disposto na Portaria 2.979/2019.

Com o subfinanciamento histórico do SUS e seu processo de desfinanciamento pela EC-95, o novo modelo de financiamento da APS, de forma neofocalizada e neoseletiva, para a população mais pobre, significa restringir mais ainda os recursos do SUS (Mendes, 2021).

Mendes (2021), aponta para os riscos da ideia de um "SUS operacional", que valoriza os atributos da modernização e racionalização das atividades estatais, associados aos interesses de mercado, consolidando uma organização de saúde com práticas de reforço a instrumentos administrativos e gerenciais, baseados em métricas, distantes do SUS universal, limitando a APS ao individualismo e assistencialismo de cunho individual.

Para Morosini et al (2020) a ênfase na pessoa assistida, desconsidera o processo social e político de produção das vulnerabilidades, tornando menos visíveis os problemas territoriais, desmotivando ações que transcendam a clínica biomédica.

Em consonância, Melo et al (2019) afirmam que a nova proposta de financiamento traz ameaças ao modelo de atenção da ESF de base comunitária e familiar, pois não favorece a implantação de ações voltadas para o território e para as populações, cruciais para a promoção da saúde e do controle de agravos e doenças. Os autores acrescem ainda o risco de que as equipes operem com número de pessoas cadastradas mais elevado (para viabilizar maior repasse de recursos com menor custo 
de contratação de profissionais e de manutenção de serviços), o que, na prática, pode significar menos equipes cobrindo mais pessoas. Por fim, os autores sinalizam que cadastro não pode ser considerado sinônimo de acesso e cuidado.

Não resta muita dúvida que este tipo de indução econômica gera a adoção de comportamentos em nível local que favorece/estimula certos tipos de práticas em detrimento de outras, e, é nesse sentido que esta seletividade de novo tipo (neoseletividade) induzida pelo novo modelo de financiamento da APS gerará uma descaracterização dos princípios do SUS na atenção básica (Mendes \& Carnut, 2020b) tais como um crescente processo de focalização da assistência em detrimento da universalização do acesso.

Diante destes desafios que se acercam, coube-nos apresentar possíveis soluções a como irão se reconfigurar os cenários de ensino na APS para a formação dos futuros profissionais de saúde em condições tão adversas ao cuidado, à integralidade, à equidade e com risco real à interprofissionalidade.

Neste sentido é que este artigo visa apresentar um produto educacional que sinaliza caminhos para reorientar a organização dos serviços da APS afim de minimizar os impactos da neoseletividade no cuidado, serviço e atenção à saúde.

\section{Metodologia}

Escrito a partir de uma metassíntese qualitativa, tendo como objeto da revisão bibliográfica os "cenários de prática no ensino superior" (objeto), qualificados pelos "desafios" (qualificador) e com amplitude limitada a "Atenção Primária à Saúde" (amplitude/limite), visou identificar os problemas já existentes sistematizados por estudos anteriores, e, trouxe a reflexão como estes problemas podem ser amenizados ou agravados em função da neoseletividade induzida pelo Previne Brasil. Assim, os resultados foram descritos e analisados à luz da neoseletividade e expõe um panorama dos cenários diante da nova proposta.

Matheus (2009) define a metassíntese qualitativa como a "integração interpretativa de achados qualitativos (derivados de estudos fenomenológicos etnográficos, da teoria fundamentada dos dados e outros), que são a síntese interpretativa dos dados" (p. 544). Afirma que as integrações mencionadas produzem uma nova interpretação dos resultados e ressalta que esta não pode ser encontrada nos estudos primários analisados. Assim, os estudos primários tornam-se os dados de uma amostra como o todo. A autora acrescenta que a metassíntese qualitativa "não é uma revisão resumida com características desvinculadas daquele evento ou daquela experiência, mas sim integra os dados a fim de alcançar um nível teórico mais elevado" (Matheus, 2009, p. 544).

Esta matriz, portanto, visa apontar soluções que podem ser tomadas pelos atores que compõem o quadrilátero da IESC (universidade, gestão, trabalhadores do SUS e usuários/controle social) no tocante a tentar sobreviver ao desfinanciamento da atenção primária e à indução macroeconômica de comportamentos racionalistas que desconfiguram vários preceitos da Atenção Primária no SUS, dentre eles o fazer integral, equitativo, interprofissional e universal.

A Matriz de Solução de Problemas (MASP) é empregada para resolver problemas e/ou oportunidades de melhoria de desempenho de uma maneira totalmente estruturada, concisa e eficiente. Este processo de melhoria apresenta etapas que contribuem para a identificação dos problemas e a elaboração de ações corretivas e preventivas para eliminá-los ou minimizálos.

Segundo Carpinetti (2012), o MASP é composto de oito fases, sendo elas:

Identificação do Problema: Nessa fase, procura-se identificar os problemas mais críticos e, portanto, mais prioritários;

Observação: objetiva a caracterização completa do problema para aumentar a chance de se identificar as causas do problema;

Análise: nessa fase, busca-se levantar as causas raízes ou fundamentais do problema em questão;

Plano de ação: depois de identificadas as supostas causas fundamentais; o objetivo desta fase é elaborar e detalhar um plano de ação para a eliminação dos efeitos indesejáveis das causas fundamentais. Ou seja, objetiva-se bloquear as causas 
fundamentais;

Ação: consiste na implementação do plano de ação;

Verificação: Consiste na avaliação de resultados para a verificação se ação foi eficaz na eliminação ou minimização do problema. Caso o resultado não tenha sido satisfatório, o processo é reiniciado pela observação e análise do problema. Caso contrário, segue-se para a próxima etapa;

Padronização: visa introduzir as ações implementadas na rotina de operação do processo ou atividade, de forma a prevenir o reaparecimento do problema;

Conclusão: o processo é finalizado com o registro de todas as ações empreendidas e resultados obtidos, para posterior recuperação de informações e históricos.

Neste caso, a primeira etapa se deu na identificação dos desafios dos cenários de prática no ensino superior na APS, após análise dos resultados da metassíntese qualitativa.

A segunda e terceira etapas foram realizadas após análise dos desafios encontrados e prospecção dos possíveis problemas que se intensificarão à luz da neoseletividade, organizados por dimensões: relacionados aos processos de trabalho, à gestão municipal, à articulação da IESC, às práticas pedagógicas e ao currículo e formação profissional.

\section{Matriz de Solução de Problemas}

\section{Desafios relacionados aos processos de trabalho}

A portaria n².436 (Ministério da Saúde, 2017), que institui a nova Política Nacional da Atenção Básica (PNAB) representa um processo de reestruturação da APS, que abrange diretrizes, formas de organização dos serviços, composição das equipes, processo de trabalho e escopo de práticas, com impactos sobre o modelo de atenção e o direito à saúde. Segundo Morosini (2017) a nova política relativiza a universalidade, recomendando a cobertura de 100\% da população apenas em áreas de grande dispersão territorial, risco e vulnerabilidade social, desestimulando a priorização da Estratégia Saúde da Família (ESF) admitindo composições de equipe e carga horária que retomam a chamada "atenção básica tradicional".

É evidente que no cenário da neoseletividade os processos de trabalho na APS deverão ser reorganizados para corresponder às metas e indicadores impostos pelo novo modelo de financiamento, o Programa Previne Brasil.

Uma das principais métricas condicionadas ao repasse financeiro é a captação ponderada, um modelo de remuneração calculado com base no número de pessoas cadastradas sob responsabilidade das equipes de Saúde da Família ou equipes de Atenção Primária.

O cadastro sempre foi uma responsabilidade de todos os profissionais na APS, porém realizado de forma efetiva pelos Agentes Comunitários de Saúde (ACS), diante da nova premissa, acresce-se a demanda de trabalho de intensificar ações de cadastramento e revisão de cadastros antigos que poderão ser considerados inválidos. É possível que discentes e docentes sejam envolvidos nessa atividade, e reconheçam sua importância se disponibilizando a colaborar, inserindo nas práticas pedagógicas as atividades de cadastramento, assim como a reflexão sobre a universalidade no SUS.

O segundo componente do Previne Brasil é o Pagamento por Desempenho, trata-se de uma transferência mensal pautada nos resultados quantitativos de diferentes indicadores monitorados e avaliados pelas equipes de saúde.

Esse componente do repasse financeiro intensificará a priorização da quantidade de atendimentos e procedimentos, restritas à atenção individual e com foco nas condições clínicas. Essa avaliação métrica poderá induzir um comportamento nos profissionais para perseguir de maneira autônoma, portanto, solitária, o alcance de suas metas, impelidos a uma rotina exaustiva, que limita as possibilidades de diálogo, ações coletivas e práticas interprofissionais.

Diante desse cenário torna-se imprescindível promover espaços de conversa e articulação entre os atores, que possibilitem a reorganização do trabalho a fim de responder às necessidades quantitativas e de acesso do serviço, e às práticas 
pedagógicas do ensino, estreitando-se o vínculo e propiciando o trabalho em equipe.

O planejamento integrado entre docentes supervisores, preceptores e equipe do serviço, deve ocorrer antes da inserção do estudante, sendo o momento em que a universidade apresenta a disciplina proposta, seu objetivo, metodologia e atividades a serem realizadas. Em contrapartida, a equipe do serviço expõe as especificidades do seu território e seus indicadores, possibilitando que, juntos, possam organizar suas práticas para atender às expectativas e necessidades de ambos.

Não apenas nesse contato, mas durante todo o período de inserção no cenário de prática, é necessária a manutenção de espaços de discussão de casos e estratégias de referência e contra-referência, que possibilitem a continuidade e longitudinalidade do cuidado, consolidando um modelo de atenção centrado na pessoa e fortalecendo o trabalho em equipe.

Um dos motivos pelo qual a atenção interprofissional ainda não é efetiva na APS, é a ausência da Educação Interprofissional (EIP) na formação em saúde. Durante o percurso estudantil, pouca, ou nenhuma, é a experiência com outras categorias profissionais, e quando inseridos no cenário de prática, o profissional, e o aluno, não são capazes de reconhecer a participação do outro e sua importância na oferta de um cuidado integral.

Nessa perspectiva, os espaços de formação e reflexão são oportunos não apenas para os alunos, mas também para as equipes, pois podem, e devem, ser aproveitados para realização de propostas de Educação Permanente em Saúde (EPS), com objetivo de qualificar o serviço. Subsidiadas pelo conhecimento técnico-científico de docentes e outros profissionais acadêmicos, as ações de EPS devem abordar temas específicos às características epidemiológicas do território, produção e qualidade de dados e ao trabalho interprofissional.

Desse modo, a EPS configura-se concretamente como um dos instrumentos potentes para a produção do cuidado humanizado, à medida que promove a formação e o desenvolvimento dos trabalhadores de saúde. Por outro lado, as metodologias ativas e problematizadoras buscam colocar em análise vivências que possibilitem a construção de uma visão crítica e reflexiva da realidade e direcionar o processo de trabalho. Nesse sentido, compreende-se que os espaços das oficinas objetivaram provocar uma reflexão do trabalho em saúde e da organização do serviço, visando uma práxis transformadora (Silva et al, 2015).

Ainda relacionada à organização dos processos de trabalho, vale ressaltar, a importância da produção de dados em saúde, principalmente no que se refere aos indicadores pactuados pelo novo modelo de financiamento. É fundamental que o sistema de informação utilizado pelo serviço seja, não apenas, apresentado à equipe da universidade, mas que sejam todos capacitados e instruídos a uma produção de dados integral, fidedigna e preferencialmente, em tempo real.

Convém ressaltar que a satisfação do trabalhador em saúde é fator impactante na qualidade do cuidado e nas relações interpessoais nesse ambiente. Aspectos relacionados à gestão do sistema de saúde local e à organização do trabalho tornam-se fatores que dificultam o desenvolvimento de suas atividades e promovem a desvalorização profissional. Nesse sentido, é imperioso reforçar o trabalho coletivo buscando agendas convergentes entre os trabalhadores, docentes e estudantes para o estudo das condições de trabalho na APS.

\section{Desafios relacionados à Gestão Municipal}

Em uma realidade de desfinanciamento proporcionado pela neoseletividade (via extinção do PAB-fixo) e ainda, relativizando o PAB-variável à critérios de produtividade, observa-se a tendência de intensificação de problemas relacionados à infraestrutura e escassez de recursos na APS.

Essa realidade compromete o desenvolvimento e qualidade dos processos de trabalho, gerando insatisfação dos profissionais, que intensificada com a inserção do ensino, exaure suas condições físicas. Uma estrutura física adequada e a disponibilidade de equipamentos e materiais necessários para execução das práticas em saúde é imprescindível contudo ainda é uma exceção na organização dos processos de trabalho nas UBS (Bousquat et al, 2017). Esta repercussão na qualidade da 
assistência e na insatisfação dos profissionais das equipes de saúde da família, alunos e comunidade certamente será intensificada com a neoseletividade induzida pelo Previne Brasil.

Contudo o Contrato Organizativo de Ação Pública Ensino-Saúde (COAPES) tem se apresentado como instrumento importante de articulação entre as IES e os serviços públicos facilitando os processos de negociação entre gestores e IES na IESC, em busca de um projeto comum. Portanto, o primeiro passo para uma integração eficaz é a contratualização conjunta e dialogada, o que torna esse instrumento, mais que um contrato, mas um referencial e guia para ações nos cenários de prática.

Perante a nova realidade imposta à APS, que tenderá ao desfinanciamento, padecendo de falta de insumos e recursos humanos, a IES e gestão municipal poderão apoiar-se em pactuações contratuais que apresentem contrapartidas materiais, ou cotas de utilização, em uma busca compartilhada de subsistência.

Também, através do COAPES, torna-se possível a articulação para representação da IES no Conselho Municipal de Saúde (CMS), que possibilita inserir nas pautas do controle social a discussão sobre a formação em saúde no SUS e a importância da IESC, não só para o ensino, mas para os serviços.

É pertinente lembrar que o Previne enfatiza modelos de Equipe de Atenção Primária (EqAP) em detrimento das Equipes de Saúde da Família (EqSF), ao seletivizar os formatos tradicionais, oferecendo-as como modelo prioritário e reforçando as deficiências estruturais da Unidades de Saúde da Família (USF). Certamente o trabalho na APS tenderá à oferta de procedimentos do núcleo mínimo, limitados à lógica do trabalho executado por esta equipe (médico, enfermeiro e cirurgiãodentista), o que acarretará a baixa inserção das diversas categorias profissionais, em formação, nestes cenários de prática, limitada pela falta de preceptoria local.

Como forma de amenizar esse obstáculo, a IES poderá organizar a integração com o serviço, alocando um docente preceptor que poderá, juntos dos alunos, oferecer o atendimento clínico, ações coletivas e atividades que ultrapassem os limites dos consultórios.

Nesse contexto, a inserção da IES no CMS possibilita trazer à agenda do gestor, e da sociedade, a reflexão sobre a importância da EqSF, em especial dos ACS e do Núcleo de Apoio à Saúde da Família (NASF), também os benefícios da inserção precoce dos discentes nos cenários de prática, para a formação profissional e para a saúde da população.

\section{Desafios relacionados à Articulação da IESC}

No cenário de neoseletividade, em que se impõe aos serviços exigências de desempenho quantitativo, que minam o cuidado individual, integral e centrado na pessoa, assim como desconsideram as ações coletivas e de educação em saúde, os processos de trabalho passam a se contrapor aos ideários de formação profissional para atuação no SUS, intensificando as dificuldades de inserção e integração, resultado da rotina de trabalho exaustiva e à precariedade das relações produtivas (Mira, Barreto \& Vasconcelos, 2016).

Possivelmente, essa realidade implicará num conflito de expectativas entre o ensino e o serviço, que dificultará arranjos institucionais, pois restringem o espaço de diálogo e uma integração efetiva, promovida através do vínculo e relações interpessoais da equipe de ensino com os profissionais do serviço, que poderão, inclusive, resistir e rechaçar à presença de alunos e docentes nos cenários de prática, sob afirmação de falta de disponibilidade.

Para superar esses desafios é necessária a criação de espaços colegiados de articulação e diálogo, em que se esclareçam as intenções, necessidades e objetivos de todos os atores envolvidos, e possibilitem a negociação e pactuação de estratégias de trabalho. Um facilitador importante é a estabilidade do docente nos cenários de prática, que favorece o vínculo com a equipe e a comunidade, estando ele ambientado às pessoas, aos processos e ao território.

Como maneira de incentivar a acolhida da academia pelas equipes dos cenários de prática, e qualificá-las permanentemente para o trabalho, é possível a pactuação, por meio do COAPES, de contrapartidas das IES que ofereçam 
possibilidade de aperfeiçoamento profissional, por meio de bolsas de estudo.

\section{Desafios relacionados às Práticas Pedagógicas}

Como já apresentado, o cenário da neoseletividade impõe aos serviços a exigência do desempenho quantitativo e poderá limitar propostas interprofissionais, de promoção à saúde, numa lógica emancipatória, de construção da autonomia e participação dos usuários, exigindo da academia uma produção exclusivamente quantitativa quando da inserção dos estudantes, que impossibilite a reflexão e criticidade das ações pedagógicas. Isto intensifica o distanciamento teoria-prática, pois reitera uma teoria para APS e uma prática para o mercado, reproduzindo uma postura profissional produtivista e pouco empática, que poderá gerar receio e descontentamento da comunidade.

Não é possível delegar a responsabilidade de produção individual à equipe de ensino, portanto é imprescindível o diálogo, articulação e organização conjunta dos processos de trabalho para que ela seja compartilhada. É importante garantir os espaços de reflexão e estudo, porém, diante do desfinanciamento eminente, a academia não pode se eximir da responsabilidade que the cabe (gradativamente), agindo de modo indiferente.

Para que as práticas pedagógicas estejam alinhadas, a equipe profissional deve estar preparada para lidar com as demandas do ensino, através de ações de capacitação e formação de preceptores na APS. Neste sentido, a prática de estudos de caso nas salas de aula aproxima a academia da realidade do trabalho e se apresentam como estratégia promissora para desenvolvimento de competências para o cuidado.

\section{Desafios relacionados ao Currículo}

É importante relembrar que a elaboração das DCNs dos cursos da área da saúde desde 2001 afirmam que a formação do profissional deve contemplar o sistema de saúde vigente no país, tendo no campo da APS um espaço privilegiado para a discussão da relevância social da universidade (Carvalho \& Ceccim, 2012).

Mesmo reconhecendo que a construção da APS nestes 27 anos vem tentando superar uma lógica interprofissional ainda frágil, hierarquizada e pouco colaborativa (Reuter et al., 2018), a proposta do Previne Brasil, interrompe e inviabiliza a efetivação dessas práticas que estavam sendo construídas gradualmente. Isso faz com que os currículos que ainda hoje são disciplinarizados ganhem com esta medida, sendo possível que os currículos tradicionais não sejam mais induzidos a mudanças, já que da forma que estão, adaptam-se bem à APS reduzida à procedimentos e a ações "financiadas" apenas para vulneráveis.

Porém, essa formação não corresponde ao perfil de egressos previstos nas Diretrizes Curriculares Nacionais (DCNS), tornando inadiável uma reestruturação curricular. À academia cabe a responsabilidade de educar o discente sobre a importância da APS como porta de entrada e ordenadora do cuidado no SUS, por meio de sua inserção precoce nesses cenários, o incentivo às ligas estudantis interdisciplinares, atividades extensionistas com a comunidade, e orientação de currículos em que desenvolvam competências para o trabalho em saúde, na lógica do cuidado longitudinal, centrado na pessoa e integral, por meio de ações colegiadas, de educação permanente e pesquisas científicas. Esse movimento pode ser iniciado pela adesão de políticas indutoras como PET Saúde e Pró Saúde.

Pautados nos desafios categorizados produzimos uma Matriz de Soluções, representada no Quadro 1, que possa reorientar as ações de IESC: 
Quadro 1. Matriz de soluções para os problemas da neoseletividade induzida nos cenários de prática na atenção primária pelo programa previne Brasil. Outubro, 2021.

\begin{tabular}{|c|c|c|c|}
\hline \multicolumn{4}{|l|}{ MATRIZ DE SOLUÇÕES } \\
\hline Desafio & Meta & Proposta & Realizadores \\
\hline \multicolumn{4}{|c|}{ Relacionados aos Processos de Trabalho } \\
\hline \multirow{2}{*}{$\begin{array}{l}\text { Intensificação das ações pontuais } \\
\text { que se chocam com a proposta de } \\
\text { longitudinalidade da APS }\end{array}$} & \multirow{2}{*}{$\begin{array}{l}\text { Reorganização dos processos de } \\
\text { trabalho para garantir vínculo e } \\
\text { continuidade do cuidado. }\end{array}$} & $\begin{array}{l}\text { Promover espaço de planejamento } \\
\text { integrado entre docentes supervisores, } \\
\text { preceptores e equipe do serviço, } \\
\text { consolidando um modelo de atenção } \\
\text { centrado na pessoa. }\end{array}$ & 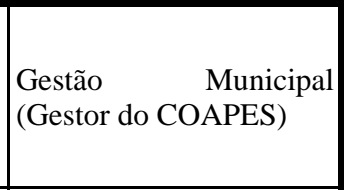 \\
\hline & & $\begin{array}{l}\text { Pactuar estratégias de referência e } \\
\text { contra-referência na relação academia } \\
\text { e equipe do serviço, estimulando a } \\
\text { comunicação e interação. }\end{array}$ & $\begin{array}{l}\text { Instituição de Ensino, } \\
\text { Gestão Municipal e } \\
\text { Equipe do Serviço }\end{array}$ \\
\hline 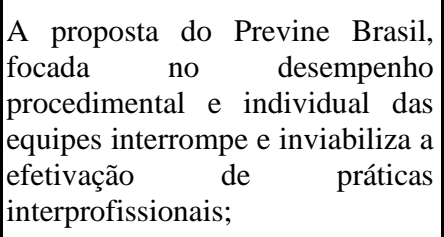 & $\begin{array}{l}\text { Organização de processos de trabalho } \\
\text { que facilitem e proporcionem o } \\
\text { diálogo e o trabalho em equipe. }\end{array}$ & $\begin{array}{l}\text { Promover a educação interprofissional } \\
\text { nos cenários de prática por meio de } \\
\text { atividades de educação permanente, de } \\
\text { modo a tornar o trabalho em equipe } \\
\text { prática comum na rotina dos serviços. }\end{array}$ & 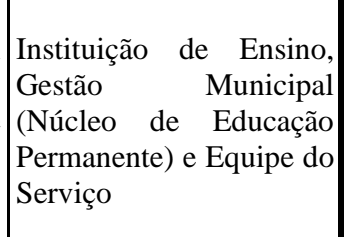 \\
\hline $\begin{array}{l}\text { Limitar as possibilidades de } \\
\text { envolvimento do aluno na APS } \\
\text { restringindo-lhes ao ofertado no } \\
\text { ambiente clínico, exigindo deles } \\
\text { produção e replicação de ações } \\
\text { procedimentais, frustrando } \\
\text { práticas reflexivas e criativas }\end{array}$ & $\begin{array}{l}\text { Reorganização dos processos de } \\
\text { trabalho. }\end{array}$ & $\begin{array}{l}\text { Articular a organização dos processos } \\
\text { de trabalho da equipe de APS e do } \\
\text { ensino de modo que garanta os } \\
\text { espaços de reflexão, discussão e } \\
\text { planejamento, possibilitando ações } \\
\text { coletivas e para além dos consultórios. }\end{array}$ & $\begin{array}{l}\text { Instituição de Ensino e } \\
\text { Equipe do Serviço }\end{array}$ \\
\hline \multirow{2}{*}{$\begin{array}{l}\text { Priorização da quantidade de } \\
\text { atendimentos e procedimentos em } \\
\text { detrimento da sua qualidade que } \\
\text { comprometerão o ensino } \\
\text { instituindo uma rotina ainda mais } \\
\text { exaustiva aos profissionais dos } \\
\text { serviços de saúde; }\end{array}$} & \multirow{2}{*}{$\begin{array}{l}\text { Reorganização dos processos de } \\
\text { trabalho em equipe, educação dos } \\
\text { profissionais para produção de dados } \\
\text { em saúde. }\end{array}$} & $\begin{array}{l}\text { Organizar os processos de trabalho } \\
\text { junto às equipes da APS de modo a } \\
\text { responder aos indicadores } \\
\text { desempenho do Programa Previne } \\
\text { Brasil, distribuindo tarefas e } \\
\text { delegando responsabilidades; } \\
\end{array}$ & $\begin{array}{l}\text { Equipe de Ensino e } \\
\text { Equipe do Serviço }\end{array}$ \\
\hline & & $\begin{array}{l}\text { Promover ações de EPS sobre a } \\
\text { importância da produção de dados em } \\
\text { saúde e sua qualidade. }\end{array}$ & $\begin{array}{|lrr|}\text { Instituição } & \text { de } & \text { Ensino, } \\
\text { Gestão } & \text { Municipal } \\
\text { (Núcleo de } & \text { Educação } \\
\text { Permanente) e } & \text { Equipe do } \\
\text { Serviço } & \\
\end{array}$ \\
\hline $\begin{array}{|lccc|}\text { Reorganização } & \text { dos processos } & \text { de } \\
\text { trabalho que } & \text { restringirá } & \text { os } \\
\text { espaços de } & \text { discussão } & \text { e } \\
\text { aprendizado. } & & \end{array}$ & 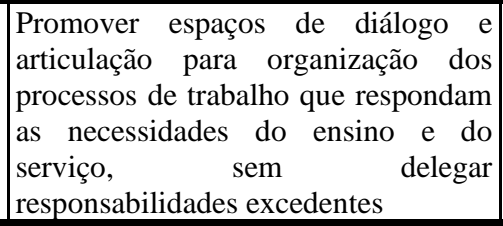 & $\begin{array}{l}\text { Reforçar o trabalho coletivo buscando } \\
\text { agendas convergentes entre } \\
\text { trabalhadores, docentes e estudantes } \\
\text { para o estudo das condições de } \\
\text { trabalho na APS }\end{array}$ & $\begin{array}{l}\text { Equipe de Ensino e } \\
\text { Equipe do Serviço }\end{array}$ \\
\hline $\begin{array}{l}\text { Desvalorização do trabalho em } \\
\text { equipe, com foco na produção } \\
\text { individual. }\end{array}$ & $\begin{array}{l}\text { Reorganização dos processos de } \\
\text { trabalho em equipe, educação dos } \\
\text { profissionais para produção de dados } \\
\text { em saúde. }\end{array}$ & $\begin{array}{l}\text { Reforçar o trabalho coletivo buscando } \\
\text { agendas convergentes entre } \\
\text { trabalhadores, docentes e estudantes } \\
\text { para o estudo das condições de } \\
\text { trabalho na APS }\end{array}$ & $\begin{array}{l}\text { Equipe de Ensino e } \\
\text { Equipe do Serviço }\end{array}$ \\
\hline $\begin{array}{l}\text { Rotinas exaustivas e maiores } \\
\text { problemas de relacionamento. }\end{array}$ & $\begin{array}{l}\text { Pactuar entre os profissionais } \\
\text { relações de bom convívio e de } \\
\text { divisão do uso dos equipamentos e } \\
\text { insumos de maneira solidária }\end{array}$ & $\begin{array}{l}\text { Espaço de EPS para maior coesão das } \\
\text { equipes e resolução de conflitos }\end{array}$ & $\begin{array}{l}\text { Núcleo de Educação } \\
\text { Permanente com apoio } \\
\text { da Instituição de Ensino }\end{array}$ \\
\hline \multicolumn{4}{|l|}{ Relacionados à Gestão Municipal } \\
\hline $\begin{array}{l}\text { Sucateamento da APS, falta de } \\
\text { insumos, recursos humanos, } \\
\text { profissionais pressionados e }\end{array}$ & $\begin{array}{l}\text { Colaborar com a gestão municipal na } \\
\text { busca de saídas compartilhadas de } \\
\text { provimento de insumos e recursos }\end{array}$ & $\begin{array}{l}\text { Cotização de materiais essenciais para } \\
\text { o trabalho na APS compartilhados } \\
\text { entre alunos, universidade e gestão. }\end{array}$ & $\begin{array}{l}\text { Instituição de Ensino e } \\
\text { Gestão Municipal }\end{array}$ \\
\hline
\end{tabular}




\begin{tabular}{|c|c|c|c|}
\hline desmotivados; & humanos & $\begin{array}{l}\text { Aproveitamento das práticas clínicas } \\
\text { com docente da universidade em } \\
\text { conjunto com aluno e sua inserção em } \\
\text { atividades coletivas e extra muro com } \\
\text { ACS e equipe. }\end{array}$ & $\begin{array}{l}\text { Instituição de Ensino, } \\
\text { Gestão Municipal e } \\
\text { Equipe do Serviço }\end{array}$ \\
\hline \multirow{2}{*}{$\begin{array}{l}\text { Oferta de procedimentos da } \\
\text { equipe mínima que intensifique a } \\
\text { baixa representatividade de outras } \\
\text { categorias profissionais na APS } \\
\text { limitando a inserção de alunos } \\
\text { por falta de preceptoria. }\end{array}$} & \multirow{2}{*}{$\begin{array}{l}\text { Articular junto à gestão municipal, } \\
\text { por meio do controle social, a } \\
\text { importância das diversas categorias } \\
\text { profissionais na APS e os benefícios } \\
\text { do trabalho interprofissional e do } \\
\text { matriciamento em saúde, que } \\
\text { possibilite o cuidado integral. }\end{array}$} & $\begin{array}{l}\text { Articular por meio do COAPES a } \\
\text { representação da IES no conselho } \\
\text { municipal de saúde; }\end{array}$ & $\begin{array}{l}\text { Instituição de Ensino e } \\
\text { Gestão Municipal }\end{array}$ \\
\hline & & $\begin{array}{l}\text { Inserir na APS os diversos cursos da } \\
\text { área da saúde, para além do currículo } \\
\text { mínimo, apresentando às equipes, ao } \\
\text { gestor, e à comunidade a importância } \\
\text { de suas ações e benefícios para } \\
\text { atenção à saúde da população. }\end{array}$ & $\begin{array}{l}\text { Instituição de Ensino e } \\
\text { Gestão Municipal }\end{array}$ \\
\hline $\begin{array}{l}\text { Tendência das } \text { EqAP serem a } \\
\text { primeira opção de um cenário } \\
\text { para inserção de } \text { alunos em } \\
\text { detrimento das EqSF }\end{array}$ & $\begin{array}{l}\text { Articular junto à gestão municipal, } \\
\text { por meio do controle social, a } \\
\text { importância da EqSF, em especial } \\
\text { ACS e núcleo de apoio. }\end{array}$ & $\begin{array}{l}\text { Inserir na APS os diversos cursos da } \\
\text { área da saúde, para além do currículo } \\
\text { mínimo, apresentando às equipes, ao } \\
\text { gestor, e à comunidade a importância } \\
\text { de suas ações e benefícios para } \\
\text { atenção à saúde da população. }\end{array}$ & $\begin{array}{l}\text { Instituição de Ensino e } \\
\text { Gestão Municipal }\end{array}$ \\
\hline \multirow{2}{*}{$\begin{array}{l}\text { Falta de insumos, equipamentos e } \\
\text { outros aspectos da estrutura } \\
\text { física. }\end{array}$} & \multirow{2}{*}{$\begin{array}{l}\text { Pressionar a administração local } \\
\text { (executivo e legislativo) a } \\
\text { comprometer parcela de seu } \\
\text { orçamento para compra de insumos } \\
\text { na APS }\end{array}$} & $\begin{array}{l}\text { Promover conscientização dos } \\
\text { estudantes ao uso racional de } \\
\text { equipamentos e insumos; }\end{array}$ & Equipe de Ensino \\
\hline & & $\begin{array}{l}\text { Pactuar contrapartidas, por meio do } \\
\text { COAPES de modo que academia não } \\
\text { onere os serviços; }\end{array}$ & $\begin{array}{l}\text { Instituição de Ensino e } \\
\text { Gestão Municipal }\end{array}$ \\
\hline $\begin{array}{l}\text { Desvalorização do } \text { trabalho } \\
\text { interprofissional, a mercê da } \\
\text { intenção do gestor municipal } \\
\text { inserir categorias profissionais } \\
\text { além da equipe mínima na APS. }\end{array}$ & $\begin{array}{l}\text { Articular junto à gestão municipal, } \\
\text { por meio do controle social, a } \\
\text { importância das diversas categorias } \\
\text { profissionais na APS, para oferta de } \\
\text { um cuidado integral. }\end{array}$ & $\begin{array}{l}\text { Articular por meio do COAPES a } \\
\text { representação da IES no conselho } \\
\text { municipal de saúde. }\end{array}$ & $\begin{array}{l}\text { Instituição de Ensino e } \\
\text { Gestão Municipal }\end{array}$ \\
\hline \multicolumn{4}{|l|}{ Relacionados à Articulação da IESC } \\
\hline $\begin{array}{l}\text { Conflito de expectativas entre o } \\
\text { ensino e o serviço que dificulta } \\
\text { arranjos institucionais que } \\
\text { valorizem a formação em saúde } \\
\text { orientada ao cuidado e centrada } \\
\text { na pessoa. }\end{array}$ & $\begin{array}{l}\text { Promover espaços de diálogo e } \\
\text { articulação para organização dos } \\
\text { processos de trabalho de modo } \\
\text { esclarecer expectativas e efetivar o } \\
\text { cuidado centrado na pessoa. }\end{array}$ & $\begin{array}{l}\text { Promover espaço de diálogo prévio a } \\
\text { inserção do estudante no serviço, } \\
\text { quando docentes possam apresentar a } \\
\text { ementa, objetivo e atividades } \\
\text { realizadas na disciplina que se insere } \\
\text { no cenário de prática. }\end{array}$ & $\begin{array}{l}\text { Equipe de ensino } \\
\text { Equipe do Serviço }\end{array}$ \\
\hline \multirow{2}{*}{$\begin{array}{l}\text { Restrição do espaço e } \\
\text { disponibilidades dos profissionais } \\
\text { da equipe da APS dialogarem ou } \\
\text { se articularem com as equipes de } \\
\text { ensino. }\end{array}$} & \multirow{2}{*}{$\begin{array}{l}\text { Reajustar a agenda de produção de } \\
\text { procedimentos visando a produção de } \\
\text { atividade mais simples que permitam } \\
\text { tempo para que os profissionais se } \\
\text { organizem e se articulem com as } \\
\text { equipes de ensino }\end{array}$} & $\begin{array}{l}\text { Promover espaços de diálogo entre } \\
\text { academia e os profissionais do } \\
\text { serviço; }\end{array}$ & $\begin{array}{l}\text { Equipe de ensino e } \\
\text { Equipe do Serviço }\end{array}$ \\
\hline & & $\begin{array}{l}\text { Oferecer por meio de contrapartidas, } \\
\text { através do COAPES, a possibilidade } \\
\text { de aperfeiçoamento profissional. }\end{array}$ & $\begin{array}{l}\text { Instituição de Ensino e } \\
\text { Gestão Municipal }\end{array}$ \\
\hline \multirow{2}{*}{$\begin{array}{l}\text { Aumento da resistência das } \\
\text { equipes da APS em receberem } \\
\text { alunos e docentes nos cenários de } \\
\text { prática. }\end{array}$} & \multirow{2}{*}{$\begin{array}{l}\text { Reavivar na mente dos profissionais } \\
\text { de saúde o papel educador que os } \\
\text { estudantes trazem à atualização do } \\
\text { profissional do serviço, como } \\
\text { também a ajuda nas atividades de } \\
\text { territorialização }\end{array}$} & $\begin{array}{l}\text { Promover espaços de diálogo que } \\
\text { apresentem com clareza as intenções } \\
\text { do ensino ao serviço; }\end{array}$ & $\begin{array}{l}\text { Instituição de Ensino e } \\
\text { Gestão Municipal }\end{array}$ \\
\hline & & $\begin{array}{l}\text { Promover estabilidade de docente nos } \\
\text { cenários de prática de modo a } \\
\text { favorecer as relações interpessoais; }\end{array}$ & Instituição de Ensino \\
\hline \multicolumn{4}{|l|}{ Relacionados às Práticas Pedagógicas } \\
\hline 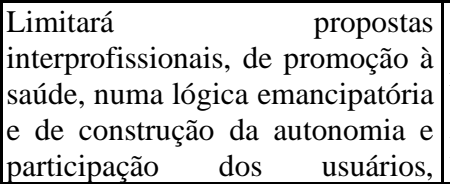 & $\begin{array}{l}\text { Garantir espaços de diálogo e } \\
\text { reflexão sobre o trabalho. Inserir nos } \\
\text { currículos de formação em saúde a } \\
\text { EIP. }\end{array}$ & $\begin{array}{l}\text { Promover ações de EPS como foco na } \\
\text { EIP, subsidiadas pela IES. }\end{array}$ & $\begin{array}{l}\text { Núcleo de Educação } \\
\text { Permanente com apoio } \\
\text { da Instituição de Ensino }\end{array}$ \\
\hline
\end{tabular}




\begin{tabular}{|c|c|c|c|}
\hline \multicolumn{4}{|l|}{$\begin{array}{l}\text { exigindo da academia uma } \\
\text { produção } \\
\text { quantitativa quando da inserção } \\
\text { dos estudantes, que impossibilita } \\
\text { a reflexão e criticidade de ações } \\
\text { no aprendizado. }\end{array}$} \\
\hline $\begin{array}{l}\text { Nova lógica de trabalho que } \\
\text { promova o distanciamento entre } \\
\text { uma teoria (para APS) e uma } \\
\text { prática (para o mercado) }\end{array}$ & $\begin{array}{l}\text { Reforçar os estudos de caso aplicados } \\
\text { a prática na APS na universidade e no } \\
\text { território. }\end{array}$ & $\begin{array}{l}\text { Utilizar métodos ativos, críticos e } \\
\text { reflexivos sobre casos reais na APS, } \\
\text { tanto no estudo na universidade com } \\
\text { no campo. }\end{array}$ & Equipe de Ensino \\
\hline 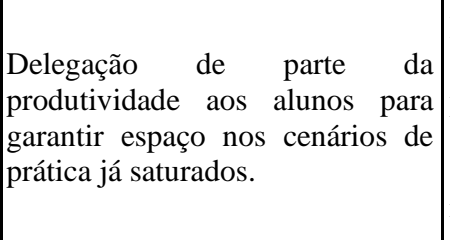 & $\begin{array}{l}\text { Promover espaços de diálogo e } \\
\text { articulação para organização dos } \\
\text { processos de trabalho que respondam } \\
\text { as necessidades do ensino e do } \\
\text { serviço, sem delegar } \\
\text { responsabilidades excedentes. }\end{array}$ & $\begin{array}{l}\text { Promover espaços de diálogo entre } \\
\text { ensino e serviço em que se apresente } \\
\text { propostas de trabalho e necessidades } \\
\text { para o desenvolvimento de práticas } \\
\text { pedagógicas, alinhando as } \\
\text { expectativas e contrapartidas. }\end{array}$ & $\begin{array}{l}\text { Equipe de ensino } \\
\text { Equipe do Serviço }\end{array}$ \\
\hline 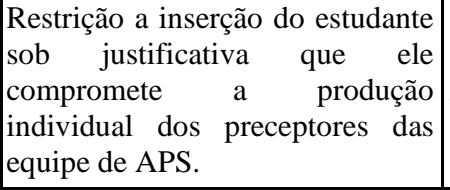 & Articulação da IES e serviços & $\begin{array}{l}\text { Promover ações de capacitação e } \\
\text { formação de preceptores na APS }\end{array}$ & $\begin{array}{l}\text { Núcleo de Educação } \\
\text { Permanente com apoio } \\
\text { da Instituição de Ensino }\end{array}$ \\
\hline \multirow[b]{2}{*}{$\begin{array}{l}\text { Postura profissional produtivista } \\
\text { e quantitativa que possa gerar } \\
\text { receio e medo na comunidade. }\end{array}$} & \multirow[b]{2}{*}{$\begin{array}{l}\begin{array}{l}\text { Articulação e vínculo com a } \\
\text { comunidade. }\end{array} \\
\end{array}$} & $\begin{array}{l}\text { Inserir a comunidade nos espaços de } \\
\text { diálogo e pactuação da IESC; }\end{array}$ & Gestor Municipal \\
\hline & & $\begin{array}{l}\text { Dar prioridade a manutenção de } \\
\text { docentes em cenários de prática na } \\
\text { APS, de modo que possibilite a } \\
\text { construção de vínculo com a a } \\
\text { comunidade. Evitar o troca-troca de } \\
\text { docentes semestral. }\end{array}$ & Instituição de Ensino \\
\hline \multicolumn{4}{|l|}{ Relacionados ao Currículo } \\
\hline $\begin{array}{l}\text { Retrocesso nas mudanças } \\
\text { curriculares em vista da educação } \\
\text { interprofissional; }\end{array}$ & $\begin{array}{l}\text { Revisitar e reestruturar currículos das } \\
\text { IES que respondam as DCNS e o } \\
\text { desenvolvimento de competências } \\
\text { para o trabalho em equipe. }\end{array}$ & $\begin{array}{l}\text { Fomentar a discussão a discussão da } \\
\text { EIP nos currículos da área da saúde }\end{array}$ & Instituição de Ensino \\
\hline $\begin{array}{l}\text { Desvalorização da APS como } \\
\text { cenário de prática e atuação } \\
\text { profissional na visão dos alunos } \\
\text { se intensificará }\end{array}$ & $\begin{array}{l}\text { Revalorizar a APS como cenário de } \\
\text { prática e futura inserção profissional } \\
\text { dos alunos }\end{array}$ & $\begin{array}{l}\text { Inserção precoce do aluno na APS } \\
\text { incentivar as ligas estudantis e } \\
\text { atividades extensionistas e o retorno à } \\
\text { comunidade do investimento social } \\
\text { feito em sua formação }\end{array}$ & Instituição de Ensino \\
\hline $\begin{array}{l}\text { Incentivo à práticas reducionistas } \\
\text { no âmbito individual que podem } \\
\text { subsidiar a manutenção de } \\
\text { currículos conservadores; }\end{array}$ & $\begin{array}{l}\text { Orientar os currículos da área da } \\
\text { saúde na lógica do cuidado } \\
\text { longitudinal, centrado na pessoa e } \\
\text { integralidade. }\end{array}$ & $\begin{array}{l}\text { Fomentar na IES as discussões das } \\
\text { práticas de cuidado com fono no } \\
\text { indivíduo e na integralidade do } \\
\text { cuidado, por meios de ações } \\
\text { colegiadas, de educação permanente e } \\
\text { pesquisas científicas. }\end{array}$ & Instituição de Ensino \\
\hline
\end{tabular}

Fonte: Autores (2021).

\section{Considerações Finais}

Os cenários de prática em saúde, como espaços de ensinar e aprender, concretizam-se na integração ensino, serviço e comunidade, por meio de relações horizontais de cooperação, tendo como eixo central o trabalho cotidiano nos serviços de saúde, garantindo espaços de reflexão e crítica da realidade. Apresenta-se, portanto, como espaços privilegiados para a transformação e consolidação dos modelos de atenção à saúde, pautados pelos valores do SUS.

Essa integração implica em mudanças nos modelos de formação, nas práticas assistências, organização dos processos de trabalho e gestão compartilhada, que possibilitem responder às necessidades do território. 
À luz da neoseletividade, e da instituição do Previne Brasil, prevê-se o desfinanciamento imediato da APS na maioria dos municípios brasileiros, e o retrocesso das práticas de atenção à saúde, descaracterizando suas ações, destituindo a ESF como prioridade e fracionando suas equipes.

A reorganização dos processos de trabalho terá impacto direto nas ações de ensino, limitando propostas interprofissionais, desconsiderando espaços de reflexão restringindo o aluno ao ambiente clínico, estimulando práticas individuais, pontuais e procedimentais, voltadas a atender as demandas de mercado e de desempenho, resultando na inserção meramente protocolar do aluno na APS.

Diante do novo contexto de atuação, o diálogo entre o ensino e o serviço tem papel decisivo na garantia da sobrevivência da APS universal e integral, coordenadora e ordenadora do cuidado, resolutiva e comprometida às necessidades reais da população.

Com base nesses pressupostos, a matriz de solução de problemas aqui apresentada é mais uma alternativa para efetivação da IESC, a partir da realidade local, possibilitando a conjugação de esforços para superação dos problemas de racionalização de custos e recursos, além dos ideais privativistas e mercantilistas que assombram a universalidade do SUS.

Nota-se a importância de estudos que reflitam sobre os caminhos para as políticas públicas que se dedicam a IESC como a instituição e valorização de espaços colegiados de deliberação e pactuação, com vistas a fortalecer o COAPES e demais políticas indutoras de inserção no ensino, assim como aqueles que preveem a inovação de currículos que promovam uma formação crítica na saúde, respondendo as necessidades assistenciais e políticas do SUS e a participação da comunidade nos processos deliberativos, de planejamento e avaliação.

\section{Referências}

Banco Mundial. Um Ajuste Justo: Análise da eficiência e equidade do gasto público no Brasil. Banco Mundial. 21 de novembro, 2017. https://documents.worldbank.org/en/publication/documents-reports/documentdetail/884 871511196609355/volume-i-s\%c3\%adntese.

BRASIL (2019), Ministério da Saúde. Portaria n. 2979 de 12 de novembro de 2019. Institui o Programa Previne Brasil. Brasília: Diário Oficial da União, ed. 220, Seção 1, p. 97. http://www.in.gov.br/en/web/dou/-/portaria-n-2.979-de-12-de-novembro-de-2019-227652180.

Bousquat, A., Giovanella, L., Fausto, M. C. R., Fusaro, E. R., Mendonça, M. H. M. de, Gagno, J., \& Viana, A. L. d’Ávila. (2017). Tipologia da estrutura das unidades básicas de saúde brasileiras: os 5 R. Cadernos de Saúde Pública, 33(8). https://doi.org/10.1590/0102-311x00037316

Carpinetti, L. C. R. (2011). Gestão da qualidade: ISO 9001: 2008: princípios e requisitos. Atlas.

Carvalho, Y. M., \& Ceccim, R. B. (2012). Formação e educação em saúde: aprendizados com a saúde coletiva. In Campos, G. W. S. et al. (orgs) In Tratado de Saúde Coletiva (pp. 137-170). Hucitec.

De Seta, M. H. et al. (2021). Programa Previne Brasil: O ápice das ameaças à Atenção Primária à Saúde? Ciência \& saúde coletiva. 26 (suppl 2), 30.

Henriques, R. L. M. (2005). Interlocução Entre Ensino e Serviço: Possibilidades de Ressignificação do Trabalho em Equipe na Perspectiva da Construção Social da Demanda. In: Pinheiro, R. \& Mattos, R. A. (Orgs). Construção social da demanda (pp. 147-159). Rio de Janeiro: IMS-UERJ/CEPESC/ABRASCO.

Marin, M. J. S. et al. (2013). Aspectos da integração ensino-serviço na formação de enfermeiros e médicos. Revista brasileira de educação médica. 37(4), 5018. http://www.scielo.br/scielo.php?script=sci_arttext\&pid=S0100-55022013000400005\&lng=en\&nrm=iso.

Matheus, M. C. C. (2009). Metassíntese qualitativa: desenvolvimento e contribuições para a prática baseada em evidências. Acta Paulista de Enfermagem, 22(spe1), 543-545. https://doi.org/10.1590/s0103-21002009000800019

Melo, E. A., Almeida, P. F. de, Lima, L. D. de, \& Giovanella, L. (2019). Reflexões sobre as mudanças no modelo de financiamento federal da Atenção Básica à Saúde no Brasil. Saúde Em Debate, 43(spe5), 137-144. https://doi.org/10.1590/0103-11042019s512

Mendes, Á. (n.d.). A persistência da aniquilação da saúde pública na crise pandêmica do capital: o neofascismo de Bolsonaro. https://www.niepmarx.blog.br/MManteriores/MM2021/Anais_MM2021/MC14_3.pdf

Mendes, A., \& Carnut, L. (2020). Capital, Estado, Crise e a Saúde Pública brasileira. SER Social, 22(46), 9-32. https://doi.org/10.26512/ser_social.v22i46.25260

Mendes, A. N. \& Carnut, L. (2020b) Crise do Capital, Estado e Neofascismo: Bolsonaro, saúde pública e atenção primária. Revista da Sociedade Brasileira de Economia Política, 57, p. 174-210.

Ministério da Saúde (2017). Portaria n 2.436, de 21 de setembro de 2017. Aprova a Política Nacional de Atenção Básica, estabelecendo a revisão de diretrizes para a organização da Atenção Básica, no âmbito do Sistema Único de Saúde (SUS). Diário Oficial da União $2017 ; 22$ set. 
Research, Society and Development, v. 11, n. 1, e37011125018, 2022

(CC BY 4.0) | ISSN 2525-3409 | DOI: http://dx.doi.org/10.33448/rsd-v11i1.25018

Mira, Q. L. M., Barreto, R. M. A., \& Vasconcelos, M. I. O. (2017). Impacto do pet-saúde na formação profissional: uma revisão integrativa. Revista Baiana de Saúde Pública, 40(2). https://doi.org/10.22278/2318-2660.2016.v40.n2.a1682

Morosini M. V. G., Fonseca A. F. \& Lima L. D. (2018) Política Nacional de Atenção Básica 2017: retrocessos e riscos para o Sistema Único de Saúde. Saúde Debate, 42, p.11-24.

Morosini, M. V. G. C. et al. (2020). Previne Brasil, Agência de Desenvolvimento da Atenção Primária e Carteira de Serviços: radicalização da política de privatização da atenção básica? Cadernos de Saúde Pública 36(9).

Reuter, C. L. O., Santos, V. C. F. dos \& Ramos, A. R. (2018). O exercício da interprofissionalidade e da intersetorialidade como arte de cuidar: inovações e desafios. Escola Anna Nery, 22(4), e20170441.

Silva, A. L. F. da, Ribeiro, M. A., Paiva, G. M. de, Freitas, C. A. S. L., \& Albuquerque, I. M. N. (2015). Saúde e educação pelo trabalho: reflexões acerca do PET-Saúde como proposta de formação para o Sistema Único de Saúde. Interface - Comunicação, Saúde, Educação, 19(suppl 1), 975-984. https://doi.org/10.1590/1807-57622014.0987

Vendruscolo, C., Ferraz, F., Prado, M. L. do, Kleba, M. E., \& Martini, J. G. (2018). Instâncias intersetoriais de gestão: movimentos para a reorientação da formação na Saúde. Interface - Comunicação, Saúde, Educação, 22(suppl 1), 1353-1364. https://doi.org/10.1590/1807-57622017.0180 